\title{
Isolation of indigenous strains of the white halo fungus as a biological control agent against 3rd instar larvae of tobacco caterpillar, Spodoptera litura (Fabricius) (Lepidoptera: Noctuidae)
}

\author{
R. Dhanapal ${ }^{1,2^{*}}$ (D, D. V. Sai Ram Kumar², R. Lakshmipathy ${ }^{3}$, C. Sandhya Rani $^{2}$ and V. Manoj Kumar ${ }^{4}$
}

\begin{abstract}
The farmer interest in biological control-based management practices using entomopathogenic fungi (EPF) for the control of many economically important insects has increased. In this process, selection of effective strains of EPF is an important criterion to control the target insect pests in efficient manner. In this context, this research work was formulated to find out environmentally effective strains of EPF in the soils of costal districts of Andhra Pradesh, India. Out of 135 soil samples collected, 9 yielded 9 strains of Lecanicillium lecanii. Among all 9 L. lecanii isolates, the least median lethal concentration $\left(\mathrm{LC}_{50}\right)$ for 3rd instar larvae of the tobacco caterpillar, Spodoptera litura (Fabricius) (Lepidoptera: Noctuidae), was $1.17 \times 10^{6}$ spores $\mathrm{ml}^{-1}$ in $\mathrm{L}-8$, followed by $1.27 \times 10^{6}$ spores $\mathrm{ml}^{-1}$ in $\mathrm{L}-5$ in an increasing order. Likewise, the median lethal time $\left(L T_{50}\right)$ values of different isolates of EPF against the 3rd instar of $S$. litura were calculated for the uniform highest concentration of $1 \times 10^{8}$ spores $\mathrm{ml}^{-1}$. Among all $9 \mathrm{~L}$. lecanii isolates, the lowest median lethal time $\left(L T_{50}\right)$ was observed as 7.70 days by $L-8$, followed by 7.77 days by $L-5$ and 8.50 days by L-7.
\end{abstract}

Keywords: Entomopathogenic fungi, Lecanicillium lecanii, Spodoptera litura, Soil isolates, White halo fungus

\section{Background}

Fungi are the most important component in most of the soil microbiota. Soil acts as main reservoir for the entomopathogenic fungi (EPF) as it protects the EPF from the degradation by sunlight. Since soil is a natural habitat for EPF, isolation of EPF involves soil sampling. Soil factors such as $\mathrm{pH}, \mathrm{EC}$, organic contents, ecosystems, and other biotic components can affect EPF activity and persistence. Occurrence of EPF in soil depends upon the availability and density of hosts, the presence of

\footnotetext{
* Correspondence: dhanapal.agri@gmail.com

'Department of Entomology, Institute of Agriculture Science, Banaras Hindu University, Varanasi, Uttar Pradesh 221005, India

${ }^{2}$ Department of Entomology, Agricultural College, Bapatla, Guntur, Andhra Pradesh 522101, India

Full list of author information is available at the end of the article
}

alternative sources of nutrition, habitat type, and environmental conditions. The EPF genera such as Beauveria, Metarhizium, Lecanicillium, and Isaria are ubiquitous components of the soil. Occurrence level of EPF in soil is affected by agricultural practices including tillage and pesticides use and distribution of particular species clades are influenced by habitat type. M. anisopliae often found in agricultural land whereas $B$. bassiana is more frequently in undisturbed habitats (Bruck et al., 2004). Lecanicillium lecanii is a deuteromycete (imperfect) fungal species widely distributed in warm and humid environments (Nunez et al. 2008). Zimmermann in 1898 was the first observed it on Lecanium viride on coffee in Indonesia. Soft-bodied insects like aphids, whiteflies, and thrips are effectively controlled by L. lecanii (Wang et al. 
2007). Few strains of L. lecanii are also found to be effective against some plant pathogenic fungi (Alavo 2015) and nematodes (Shinya et al. 2008). Knowledge of local species composition and distribution is important, if the indigenous populations of EPF in the soil are to be managed in ways to facilitate the control of pest insect populations within the agro-ecosystem (Meyling and Eilenberg 2007). Zimmermann (1986) proposed the "insect bait method" (in vivo) for the isolation of entomogenous fungi from soil, which allows investigations on spectrum composition and frequency of these insect pathogens in soil habitat as compared to the selective medium method (in vitro) (Korosi et al. 2019). The "insect bait method" has been widely used for isolating EPF from soils in different parts of the world (Deaver et al. 2019).

Tobacco caterpillar, Spodoptera litura (Fabricius) (Lepidoptera: Noctuidae), is a polyphagous insect pest, which feeds on more than 120 food crops in all over the world of which 40 are grown in India (Chandra Teja and Rahman 2020). In India, it causes damage to economically important crops like: tobacco, cotton, tomato, onion, groundnut, cabbage, cauliflower, brinjal, and turnip. $S$. litura causes 35 to $55 \%$ yield losses at the flowering and vegetative stages of the crop (Asi et al. 2013). There are several methods such as physical, mechanical, cultural, biological, and chemical methods to control these economically important pests. Among all, insecticide application is the most commonly used control method by farmers. However, excessive application of insecticides creates ecological imbalances by destruction of natural enemies (parasitoids and predators) and non-target organisms (Mkenda et al. 2020). In addition, the insecticide application invites 3 R's problems such as resistance, resurgence in insect pests, and residues on food crops (Mantzoukas 2020). Hence, it is important to use integrated pest management (IPM) strategies utilizing natural enemies, which provide similar efficacy against S. litura (Srinivasan 2012 and El Husseini 2019). Majority of the insecticides does not kill economically important pests due to development of resistance to insecticides. In that situation, biological control method is recommended to reduce insect population below the economic threshold level (ETL). Control of insect pest by using local isolates of EPF is an effective method to reduce the insecticide resistance and resurgence problems (Goble et al. 2011), and these local isolates also have more chances of more survival and persistence with better adaptability to local climatic conditions (Sain et al. 2019). The success of insect control using EPF is based on a correct selection of strains which has adapted to climatic conditions. Most of the farmers of Andhra Pradesh, India, are using nonnative isolates of EPF for insect control. Hence, in this context, this study was formulated to find out efficient indigenous strains of white halo fungus, Lecanicillium lecanii, from soils of Coastal Andhra Pradesh, India, and their pathogenicity against tobacco caterpillar, S. litura.

\section{Materials and methods \\ Collection of soil samples}

The soil was sampled from 3 biotopes such as agricultural land, forest land/orchard land, and barren lands from the diverse locations of 9 districts of coastal Andhra Pradesh, India. One hundred thirty-five soil samples were collected. In each habitat, 4 soil samples were taken at $10 \mathrm{~cm}$ depth. Since greater wax moth, Galleria mellonella L., is the most sensitive to be attacked by EPF and entomopathogenic nematode, G. mellonella was used to isolate the EPF from soil samples (Zimmerman 1986). Soil samples were transferred to the laboratory and stored in $4{ }^{\circ} \mathrm{C}$ in refrigerator. At isolation time, soil samples were sieved and removed the debris. The fine particle of soil was collected and watered to create favorable condition for fungus.

\section{Fungal isolation and maintenance}

Approximately, $70 \mathrm{~g}$ of soil was weighed and transferred to small sterile plastic disposable containers and $5 \mathrm{G}$. mellonella larvae of final instar of were released into each container and incubated for 1 week under laboratory conditions. After inoculation of the larvae in soil, it was examined every day. The infected cadavers were washed with $2 \%$ sodium hypochloride $(\mathrm{NaOCl})$ and serially washed 3 times with distilled water. The fungi were grown on PDA medium. It was purified by single spore isolation method (Rangaswami 1971) and maintained by regular sub culturing on PDA medium (Prasad Uday et al. 2016).

\section{Testing isolated EPF against S. litura larvae}

The larvae of S. litura were used for testing the efficacy of isolated EPF. Under laboratory conditions of $27 \pm$ $2{ }^{\circ} \mathrm{C}$ and 60 to $70 \% \mathrm{RH}$, S. litura larvae were reared on natural host castor bean leaves. The 3rd instar larvae of S. litura were dipped individually for $30 \mathrm{~s}$ in different concentrations $\left(1 \times 10^{4}, 1 \times 10^{5}, 1 \times 10^{6}, 1 \times 10^{7}\right.$, and 1 $\times 10^{8}$ spores $\mathrm{ml}^{-1}$ ) of fungal spore suspensions of isolated EPF prepared by serial dilution method (Asi et al. 2013). Spores were counted by Neubauer hemocytometer. In control, the larvae were treated only by $0.02 \%$ Tween 80 . The treated larvae were left freely on tissue paper in a Petri plate to remove the excess moisture. After air drying, the treated larvae were fed by fresh and clean castor leaves for $15 \mathrm{~min}$. At $24 \mathrm{~h}$ interval, the leaves were periodically replaced with fresh ones. The dead larvae were incubated on moist filter paper for confirmation of EPF sporulation daily. Thirty larvae per treatment with 3 replications were maintained in each 
Table 1 Fungal codes, districts, and habitats of Coastal Andhra Pradesh, India

\begin{tabular}{lll}
\hline Fungal code & District & Habitat \\
\hline L-1 & Srikakulam & Forest land \\
L-2 & Visakapatnam & Orchard land \\
L-3 & Srikakulam & Social forest land \\
L-4 & Vizianagaram & Orchard land \\
L-5 & Prakasam & Barren land \\
L-6 & Krishna & Orchard land \\
L-7 & Nellore & Orchard land \\
L-8 & East Godavari & Barren land \\
L-9 & Visakapatnam & Forest land \\
\hline
\end{tabular}

experiment. The larval data were recorded daily for 14 days after treatment (Erper et al. 2016). Mortality rate was recorded in the control category also for Abbott's correction (Abbott 1925). All experiments were repeated in triplicate.

\section{Statistical analysis}

The $\mathrm{LC}_{50}, \mathrm{LC}_{90}, \mathrm{LT}_{50}$, and $\mathrm{LT}_{90}$ values were derived from logarithmic calculations (Finney 1984) using multiple linear program. The data were analyzed by probit analysis, using analysis of variance (ANOVA) technique (Gomez and Gomez 1984,) using SPSS program.

\section{Results and discussion}

In the present study, soil samples were surveyed and collected from 3 locations each (agricultural land, barren land, orchard/forest land) of 5 mandals each in 9 districts of Coastal Andhra Pradesh, India. In search of local strains of $L$. lecanii from the soils of coastal districts of Andhra Pradesh, 9 isolates of L. lecanii were isolated from 135 soil samples collected. Each isolate was designated as L-1, L-2, L-3, L-4, L-5, L-6, L-7, L-8, and L-9 (Table 1). This is facultative pathogen. During dearth phase of the host, this can develop in soils as saprophytic fungi, which is very important for their survival. The habitats affect the occurrence of EPF in the soil. Most of the L. lecanii strains were isolated from orchard/forest land, followed by barren land in the order of occurrence of fungi in the soil. The survey showed that L. lecanii is commonly found in soils of Coastal Andhra Pradesh, particularly natural and undisturbed habitats. Identification of EPF was undertaken depending upon colony morphology, size, and shape of conidia. Colonies were suede-like white in color. Conidiophores are little differentiated from vegetative hyphae. Conidiogenous cells (phialides) are in whorls (verticals) of 2-6, paired, or solitary on hyphae or apically on short side branches. Conidia is hyaline and aseptate, borne in slime droplets or dry chains. The growth rate of L. lecanii was fast (Vivekanandhan et al. 2020). Identification of the different isolates of L. lecanii was also confirmed by the National Bureau of Agricultural Insect Resources (NBAIR), Bengaluru, India.

L. lecanii was mostly found in forest/orchard land. The forest/orchard habitat has a high organic matter content and is well protected from UV light. Due to which, L. lecanii was found mostly in forest/orchard land. Most of the forest/orchard land soils are undisturbed, and occurrence of root feeding forest or orchard plant insects also accounted for the occurrence of $L$. lecanii in the soils. Unlike $M$. anisopliae, the $L$. lecanii are sensitive to application of chemical pesticides and other agricultural practices. This also can be accounted for the absence of L. lecanii in the agricultural soils. EPF occurred more commonly in soils from organically managed arable fields than with conventionally ones, in which synthetic insecticides had greatly reduced the availability of suitable hosts (Klingen et al. 2002). The spore production and conidial germination of L. lecanii are highly affected by spraying of agrochemicals in the field (Gonzalez et al. 2012). And also, the application of agrochemicals in the agricultural field kills insects, which are present in the soil due to which the EPF occurrence also reduced.

Table 2 Mortality response of 3rd instar larvae of Spodoptera litura to different fungal isolates of Lecanicillium lecanii

\begin{tabular}{|c|c|c|c|c|c|c|}
\hline Fungal isolates & Heterogeneity $\left(x^{2}\right)$ & Regression equation & $\mathrm{LC}_{\mathbf{5 0}}\left(\right.$ spores $\mathrm{ml}^{-\mathbf{1}}$ ) & Fiducial limit @ 50\% & $\mathrm{LC}_{\mathbf{9 0}}$ (spores $\mathrm{ml}^{\mathbf{- 1}}$ ) & Fiducial limit @ 90\% \\
\hline L-1 & 0.61 & $y=0.277 x+3.158$ & $4.42 \times 10^{6}$ & $6.76 \times 10^{5}-2.89 \times 10^{7}$ & $2.08 \times 10^{11}$ & $2.28 \times 10^{8}-1.89 \times 10^{14}$ \\
\hline$L-2$ & 1.47 & $y=0.279 x+3.076$ & $7.68 \times 10^{6}$ & $1.01 \times 10^{6}-5.82 \times 10^{7}$ & $3.82 \times 10^{11}$ & $2.72 \times 10^{8}-5.36 \times 10^{14}$ \\
\hline L-3 & 1.53 & $y=0.439 x+2.166$ & $3 \times 10^{6}$ & $9.41 \times 10^{5}-9.57 \times 10^{6}$ & $2.40 \times 10^{9}$ & $1.27 \times 10^{8}-4.53 \times 10^{10}$ \\
\hline L-4 & 0.32 & $y=0.332 x+3.054$ & $7.03 \times 10^{5}$ & $1.61 \times 10^{5}-3.06 \times 10^{6}$ & $5.54 \times 10^{9}$ & $7.80 \times 10^{7}-3.94 \times 10^{11}$ \\
\hline L-5 & 1.48 & $y=0.331 x+2.971$ & $1.27 \times 10^{6}$ & $2.88 \times 10^{5}-5.61 \times 10^{6}$ & $1.12 \times 10^{10}$ & $1.14 \times 10^{8}-1.10 \times 10^{12}$ \\
\hline L-6 & 0.51 & $y=0.319 x+2.954$ & $2.52 \times 10^{6}$ & $5.33 \times 10^{5}-1.19 \times 10^{7}$ & $2.64 \times 10^{10}$ & $1.76 \times 10^{8}-3.96 \times 10^{12}$ \\
\hline L-7 & 1.91 & $y=0.293 x+3.038$ & $4.98 \times 10^{6}$ & $8.03 \times 10^{5}-3.09 \times 10^{7}$ & $1.48 \times 10^{10}$ & $2.57 \times 10^{8}-8.54 \times 10^{12}$ \\
\hline L-8 & 0.17 & $y=0.356 x+2.841$ & $1.17 \times 10^{6}$ & $2.97 \times 10^{5}-4.58 \times 10^{6}$ & $5.00 \times 10^{9}$ & $1.01 \times 10^{8}-2.48 \times 10^{11}$ \\
\hline L-9 & 0.81 & $y=0.318 x+2.959$ & $2.56 \times 10^{6}$ & $5.29 \times 10^{5}-1.24 \times 10^{7}$ & $3.03 \times 10^{10}$ & $1.77 \times 10^{8}-5.17 \times 10^{12}$ \\
\hline
\end{tabular}


The presence and activity of EPF in soils may be affected by many factors such as $\mathrm{pH}, \mathrm{EC}$, organic matter, and soil type (Bouamama et al. 2010). The soil factors such as organic matter and soil texture are highly affecting the occurrence of EPF in soil (Moloinyane et al. 2020), whereas $\mathrm{pH}$ and $\mathrm{EC}$ do not affect the presence or absence of EPF in soil (Karthick et al. 2013). High organic matter in the soil helps the EPF in the adsorption, and also, high organic matter increases the diversity and density of the insect host, which helps in the multiplication and metabolism of EPF in soil (Klingen and Haukeland 2006 and Sularno et al. 2019). Various studies reported the effects of soil factors such as geographical location, soil habitat, soil texture, organic matter, $\mathrm{pH}$, and $\mathrm{EC}$ on the occurrence of EPF in the soils where the presence of EPF was found to be high in the soils containing more organic matter and a high nitrogen content, while soil $\mathrm{pH}, \mathrm{EC}$, and geographical position did not affect the occurrence of EPF in soil (Karthick et al. 2013). In the present study, the forest or orchard land soils yielded more EPF and are more protected from the sunlight and contain more organic matter, which may be the responsible for the occurrence of EPF in that soils. Likewise, Beauveria bassiana also present more sensitive to agrochemicals and mostly present in the undisturbed forest soils.

Among the $9 \mathrm{~L}$. lecanii isolates, the least median lethal concentration $\left(\mathrm{LC}_{50}\right)$ for 3 rd instar of $S$. litura was $1.17 \times 10^{6}$ spores $\mathrm{ml}^{-1}$ recorded in L-8, followed by $1.27 \times 10^{6}$ spores $\mathrm{ml}^{-1}$ in L-5 in an increasing order. Then, the remaining isolates of $L$. lecanii had shown their $\mathrm{LC}_{50}$ at $2.56 \times 10^{6}$ spores $\mathrm{ml}^{-1}$ in $\mathrm{L}-9,3$ $\times 10^{6}$ spores $\mathrm{ml}^{-1}$ in L-3, $2.52 \times 10^{6}$ spores $\mathrm{ml}^{-1}$ in L-6, $4.42 \times 10^{6}$ spores $\mathrm{ml}^{-1}$ in L-1, $4.98 \times 10^{6}$ spores $\mathrm{ml}^{-1}$ in $\mathrm{L}-7,7.03 \times 10^{5}$ spores $\mathrm{ml}^{-1}$ in $\mathrm{L}-4$, and 7.68 $\times 10^{6}$ in $\mathrm{L}-2 . \mathrm{LC}_{90}$ also followed the trend of $\mathrm{LC}_{50}$. The values of $\chi^{2}$, regression equation, and fiducially limits corresponding to different $\mathrm{LC}_{50}$ and $\mathrm{LC}_{90}$ values of different isolates of L. lecanii were presented in Table 2. The lowest median lethal time $\left(\mathrm{LT}_{50}\right)$ values for different isolates of $L$. lecanii against 3 rd instar of $S$. litura were calculated for a common concentration of $1 \times 10^{8}$ spores. $\mathrm{ml}^{-1}$. The $\mathrm{LT}_{50}$ was observed as 7.70 days at L-8, followed at 7.77 days at L5 and 8.50 days at L-7. The values of $\chi^{2}$, regression equation, and fiducially limits corresponding to different $\mathrm{LT}_{50}$ and $\mathrm{LT}_{90}$ values of different isolates of $L$. lecanii are presented in Table $3 . \mathrm{LT}_{50}$ of $S$. litura showed prolongation with decreases in tested concentrations of L. lecanii (Table 3).

The $\mathrm{LC}_{50}$ and $\mathrm{LT}_{50}$ of EPF were determined by reference to 50 and $90 \%$ mortality rates of the 3rd instar $S$. litura larvae after immersing them in fungal conidial suspension for few seconds (Asi et al. 2013). Almost similar results were reported by Loureiro et al. (2004) who found an increase in mortality with the increase in time and concentration. However, there might be differences in mortality rates due to difference in strains being evaluated, concentration, and laboratory conditions. After $48 \mathrm{~h}$ of treatment, the larvae stopped feeding and became sluggish. The treated larval cuticle became blackened, which may be due to melanization. QuesadaMoraga et al. (2006) reported that the effectiveness of EPF begun after $48 \mathrm{~h}$ of the penetration of EPF into integument and at $96 \mathrm{~h}$, the complete destruction of gut epithelium was observed. This may be due to the profuse production of toxic proteins and enzymes in the insect body.

\section{Conclusion}

An attempt to isolate indigenous strains of the white halo fungus, L. lecanii, from soils of Coastal Andhra Pradesh, India, and to find out the efficient strain to control lepidopteran insect was undertaken. Among 9 soil strains, L-8 and L-5 were the most appropriate strains for further formulation and field application. The obtained results confirmed the possibility of using this fungus in controlling larvae of S. litura.

Table 3 Time mortality response of 3rd instar larvae of Spodoptera litura to different fungal isolates of Lecanicillium lecanii

\begin{tabular}{lllllll}
\hline Fungal isolates & Heterogeneity $\left(x^{2}\right)$ & Regression equation & $L_{\mathbf{5 0}}$ (days) & Fiducial limit @ 50\% & LT $_{\mathbf{9 0}}$ (days) & Fiducial limit @ 90\% \\
\hline L-1 & 9.83 & $y=2.152 x-0.616$ & 8.60 & $7.92-9.33$ & 17.28 & $14.92-20.02$ \\
L-2 & 7.57 & $y=2.235 x-0.750$ & 8.72 & $8.02-9.48$ & 17.97 & $15.38-21.00$ \\
$L-3$ & 13.00 & $y=1.984 x-0.357$ & 8.83 & $8.13-9.60$ & 17.33 & $14.94-20.11$ \\
L-4 & 7.26 & $y=2.152 x-0.616$ & 8.97 & $8.20-9.81$ & 18.96 & $15.97-22.52$ \\
L-5 & 16.05 & $y=1.774 x+0.466$ & 7.77 & $7.08-8.52$ & 18.32 & $15.44-21.75$ \\
L-6 & 7.12 & $y=2.218 x-0.719$ & 8.84 & $8.11-9.63$ & 18.49 & $15.70-21.76$ \\
L-7 & 12.13 & $y=2.045 x-0.459$ & 8.50 & $7.84-9.21$ & 16.47 & $14.36-18.90$ \\
$L-8$ & 16.81 & $y=1.774 x+0.465$ & 7.70 & $7.02-8.44$ & 17.99 & $15.22-21.26$ \\
$L-9$ & 9.49 & $y=2.203 x-0.718$ & 8.54 & $7.88-9.27$ & 17.02 & $14.73-19.67$ \\
\hline
\end{tabular}




\section{Acknowledgements}

The authors wish to highly gratefully thank Dr. B. Ramanujam, Principal Scientist, NBAIR, Bengaluru, for his valuable identification of entomopathogenic fungi.

\section{Authors' contributions}

The conception and design of the study were done by all authors. RD collected the soil samples from the nine coastal Andhra Pradesh, India, isolated entomopathogenic fungi from soil and preparation of the manuscript. DV helped in the pathogenicity of entomopathogenic fungi against tobacco caterpillar. RL and V authors helped in the identification of entomopathogenic fungi. $\mathrm{C}$ helped in the maintenance of Spodoptera litura and Galleria mellonella. All the authors read and approved the manuscript.

\section{Funding}

This work was not supported by any funding body.

\section{Availability of data and materials}

The data and material used during the current study are available from the corresponding author on reasonable request.

\section{Ethics approval and consent to participate}

I agree to all concerned regulations.

\section{Consent for publication}

I agree to publish this scientific paper in the EJBPC.

\section{Competing interests}

The author declares that he/she has no competing interests.

\section{Author details}

${ }^{1}$ Department of Entomology, Institute of Agriculture Science, Banaras Hindu University, Varanasi, Uttar Pradesh 221005, India. ${ }^{2}$ Department of Entomology, Agricultural College, Bapatla, Guntur, Andhra Pradesh 522101, India. ${ }^{3}$ Department of Microbiology, Agricultural College, Bapatla, Guntur, Andhra Pradesh 522101, India. ${ }^{4}$ Department of Plant Pathology, Agricultural College, Bapatla, Guntur, Andhra Pradesh 522101, India.

Received: 1 April 2020 Accepted: 23 June 2020

Published online: 08 July 2020

\section{References}

Abbott WS (1925) A method of computing the effectiveness of an insecticide. Econ Entomol 18:265-267

Alavo TB (2015) The insect pathogenic fungus Verticillium lecanii (Zimm.) Viegas and its use for pests control: a review. J Exp Biol p 3.

Asi MR, Bashir MH, Afzal M, Zia K, Akram M (2013) Potential of entomopathogenic fungi for biocontrol of Spodoptera litura Fabricius (Lepidoptera: Noctuidae). J Anim Plant Sci 23(3):913-918

Bouamama N, Vidal C, Fargues J (2010) Effects of fluctuating moisture and temperature regimes on the persistence of quiescent conidia of Isaria fumosorosea. J Invertebrate Pathol 105(2):139-144

Bruck DJ (2004) Natural occurrence of entomopathogens in Pacific Northwest nursery soils and their virulence to the black vine weevil, Otiorhynchus sulcatus (F.) (Coleoptera: Curculionidae). Environ Entomol 33:1335-1343

Chandra Teja KNP, Rahman SJ (2020) Virulence of local isolates of entomopathogenic fungi on the common agricultural pest Spodoptera litura (Fabricius) (Lepidoptera:Noctuidae). Int J Curr Microbiol App Sci 9(02):2768-2778

Deaver NR, Hesse C, Kuske CR, Alfaro AP (2019) Presence and distribution of insect - associated and entomopathogenic fungi in a temperate pine forest soil: an integrated approach. Fung biol 123(2):864-874

El Husseini MMM (2019) Efficacy of the entomopathogenic fungus, Metarhizium anisopliae (Metsch.), against larvae of the cotton leafworm, Spodoptera littoralis (Biosd.) (Lepidoptera: Noctuidae), under laboratory conditions. Egypt J Biol Pest Control 29:50

Erper I, Saruhan I, Akca I, Aksoy HM, Tuncer C (2016) Evaluation of some entomopathogenic fungi for controlling the Green Shield Bug, Palomena prasina L. (Heteroptera: Pentatomidae). Egypt J Biol Pest Control 26(3):573-578

Finney DJ (1984) Probit analysis. Cambridge University Press, London, p 333
Goble TA, Dames JF, Hill MP, Moore SD (2011) Investigation of native isolates of entomopathogenic fungi for the biological control of three citrus pests. Biocontrol Sci Techn 21:1193-1211

Gomez KA, Gomez AA (1984) Statistical procedures for Agricultural Research, 2nd edn. International Rice Research Institute, Philippines, p 680

Gonzalez LC, Nicao MEL, Muino BL, Perez RH, Sanchez DG, Martinez VL (2012) Effect of six fungicides on Lecanicillium (Verticillium) lecanii (Zimm.) Zare \& Gams, J Food Agric Environ. 10:1142-1145

Karthick RN, Bharani RSA, Ansari MR (2013) Natural occurrence of potential fungal biopesticide Nomuraea rileyi (Farlow) Samson associated with agriculture fields of Tamil Nadu, India and it's compatibility with metallic nanoparticles. J Biofertilizers Biopest 4(1):2-7

Klingen I, Eilenberg J, Meadow R (2002) Effects of farming system, field margins and bait insect on the occurrence of insect pathogenic fungi in soils. Agric Ecosyst Environ 91:191-198

Klingen I, Haukeland S (2006) The soil as a reservoir for natural enemies of pest insects and mites with emphasis on fungi and nematodes. In: Eilenberg J, Hokkanen HMT (eds) An Ecological and Societal Approach to Biological Control. Springer, The Netherlands, pp 145-211

Korosi GA, Wilson BAL, Powell KS, Ash GJ, Reineke A, Savocchia S (2019) Occurrence and diversity of entomopathogenic fungi (Beauveria spp. and Metarhizium spp.) in Australian vineyard soils. J Invertebr Pathol 164:69-77

Loureiro ES, Oliveira NC, Wilcken CF, Batista AB (2004) Patogenicidade de Verticillium lecanii ao pulgão-do-pinus. Rev Árvore 28:765-770

Mantzoukas S, Eliopoulos PA (2020) Endophytic entomopathogenic fungi: a valuable biological control tool against plant pests. Appl Sci 10:360

Meyling NV, Eilenberg J (2007) Ecology of the entomopathogenic fungi Beauveria bassiana and Metarhizium anisopliae in temperate agroecosystems: potential for conservation biological control. Biol Cont 43(2):145-155

Mkenda PA, Ndakidemi PA, Stevenson PC, Arnold SE, Darbyshire I, Belmain SR, Priebe J, Johnson AC, Tumbo J, Gurr GM (2020) Knowledge gaps among smallholder farmers hinder adoption of conservation biological control. Biocontrol Sci Techn 30(3):256-277

Moloinyane S, Addison P, Achiano KA, Nchu F (2020) Association between chemical properties of vineyard soils and occurrence of entomopathogenic fungi causing different levels of mortality in Planococcus ficus. BioControl. https://doi.org/https://doi.org/10.1007/s10526-019-09989-3.

Nunez E, Lannacone J, Gomez H (2008) Effect of two entomopathogenic fungi in controlling Aleurodiccus coccois (Curtis, 1846) (Hemiptera: Aleurodidae). Chil J Agric Res 68(1):21-30

Prasad Uday US, Bandyopadhyay TK, Goswami S, Bhunia B (2016) Optimization of physical and morphological regime for improved cellulase free xylanase production by fed batch fermentation using Aspergillus niger (KP874102. 1) and its application in bio-bleaching. Bioengineered 8(2):1-10

Quesada-Moraga E, Carrasco-Diaz JA, Santiago-Alvarez C (2006) Insecticidal and antifeedant activities of proteins secreted by entomopathogenic fungi against Spodoptera littoralis (Lep., Noctuidae). J Appl Entomol 130:442-452

Rangaswami G (1971) Diseases of crop plants in India. Prentice Hall of India Pvt. Ltd., New Delhi, p 520

Sain SK, Monga D, Kumar R, Nagrale DT, Hiremani NS, Kranthi S (2019) Compatibility of entomopathogenic fungi with insecticides and their efficacy for IPM of Bemisia tabaci in cotton. J Pestic Sci 44(2):97-105

Shinya R, Aiuchi D, Kushida A, Tani M, Kuramochi Kand Koike M (2008) Effects of fungal culture filtrates of Verticillium lecanii (Lecanicillium spp.) hybrid strains on Heterodera glycines eggs and juveniles. J Invertebr Pathol 97:291-297

Srinivasan R (2012) Integrating biopesticides in pest management strategies for tropical vegetable production. J Biopestic pp:36-45

Sularno AE, Fefiani Y (2019) Abundance and diversity of entomopathogenic fungi in Sibolangit conservation forest and Berastagi vegetable land. Int J Lang Res Educ Stud 3(1):127-136

Vivekanandhan P, Bedini S, Shivakumar MS (2020) Isolation and identification of entomopathogenic fungus from Eastern Ghats of South Indian forest soil and their efficacy as biopesticide for mosquito control. Parasitol Int 76:1-27

Wang L, Huang J, You M, Guan X, Liu B (2007) Toxicity and feeding deterrence of crude toxin extracts of Lecanicillium (Verticillium) lecanii (Hyphomycetes) against sweet potato whitefly, Bemisia tabaci (Homoptera: Aleyrodidae). Pest Manag Sci 63:381-387

Zimmermann G (1986) "Galleria bait method" for detection of entomopathogenic fungi in soil. J Appl Entomol 102:213-215

\section{Publisher's Note}

Springer Nature remains neutral with regard to jurisdictional claims in published maps and institutional affiliations. 